\title{
Project Planning and Macro Planning
}

\section{Hugh Latimer}

Despite setbacks, such as the public reaction to the high cost of the apparently wasted Third London Airport Study, protagonists of project evaluation and social cost-benefit analysis have advanced steadily in self-confidence and ambition in the past 15 years, while macro-planners, whose disciplines are still dominant in the teaching of planing, have been on the defensive. For evidence on this one need only compare the qualifications entered by the joint authors of the first popular survey of the state of the art, Professor Prest and Mr. Turvey, in 1965, with the assurance with which the World Bank manual of 1975 (Squire and van der Tak 1975) lays down means whereby governments of sovereign states shall derive interpersonal and inter-temporal preference functions. Not only has the art advanced beyond the single criterion of economic growth per caput to include also income distribution objectives (notably in Little and Mirrlees 1974; UNIDO 1972; and Squire and van der Tak 1975) but it is now taken for granted that choices are possible and desirable between projects in different sectors by means of common weights and a common test rate of social profitability. In sectors where benefits are difficult to measure, cost saving can be taken as benefit, and this in theory enables a government to decide, for instance, that an investment in a by-pass or in a health facility is a more efficient use of resources than a particular investment in a directly productive industry ${ }^{1}$. That cost benefit analysis is apparently applied more in developing than in developed countries derives from the greater state involvement in the economy in developing countries, the influence of the World Bank and other lenders, and the theoretically greater distortion of domestic prices in a world free from the GATT.

Cost-benefit analysis is, however, still at a halfway house. Let us extrapolate the trend a few years and suppose that it has advanced in the following directions:

-It has advanced beyond the stage of partial analysis to take into account all first round and

\footnotetext{
I Though the values to be placed on this benefit, as also in the stream of income method, derive eventually from the world traded values of directly productive output.
}

systems effects ${ }^{2}$, as well as secondary effects in conditions in which these are appropriate (mainly in regional analysis and in countries where alternative projects to that analysed are not available for any reason);

- It has systematically taken account of the alternate opportunities for all factors offered by international trade;

-It has incorporated in the objective functions not only growth and income distribution objectives, but the whole range of other merit wants' found, for example, in a list of objectives of spatial planners;

-A working system of project appraisal and control operates at the centre of economic government.

Nearly all these conditions are already within reach of fulfilment. Systems project analysis is common in large state-owned enterprises such as the electricity and steel systems of Britain and France; a host of research workers are engaged on deriving accounting prices and conversion factors at traded prices in various countries; the methodology of taking into account other objectives has been outlined, notably by Marglin (1967), and remains only to be put into practice; many countries have in embryo or youthful form what Little and Mirrlees describe as a COPE (Central Office of Project Evaluation) (Little and Mirrlees 1974:88). 'Impact studies' of small or regional economies, notably in the field of tourism, are throwing much more light on secondary costs and benefits (see for example Archer 1973). True, overall models of economics in the transportation field have tended to combine poor predictive performance and excessive $\operatorname{cost}^{3}$. But for the purpose of the argument of this paper it is not necessary to assume that project analysis will necessarily become more refined, nor even more accurate, merely that it will become more generally accepted and will broaden its scope.

If this is so, it is reasonable to predict that project preparation, appraisal and implementation

2 This is correct project appraisal procedure, but too often the net cash flow from an investment is taken without accounting for any loss of sales occasioned to other producers, correct only under conditions of perfect competition and marginal substitutability of factors. An attempt to systematise the more realistic approach is made by Prou and Chervel, 1970.

3 For instance the 'Harvard model' bought by IBRD and applied to Columbia. 
procedures will take over much of the ground at present occupied by medium-term comprehensive planning. This happens already whenever-and that is frequently-the Plan is temporarily in abeyance, because of a change in government, an economic crisis, the obsolescence of the previous Plan or the failure of a new Plan to be prepared in time.

Many central planners of project appraisal have only hazy ideas of the technique and make simple errors; some consider the simple accounting procedures needed below their intellectual dignity and have been guilty of wasting their country's resources through negligence. Indeed, in one perspective the two decades spent chasing the chimera of comprehensive state planning have been a waste of scarce resources of trained manpower; more real development would probably have ensued if the hours of study spent building inoperative five year plans had been spent instead on managerial or financial control. The growing disillusion with macro-economic mediumterm planning has been documented fully enough elsewhere (see Caiden and Wildavsky 1974; Waterston 1965; Faber and Seers 1972; Killick 1976; Latimer 1977). However, if project planning is increasingly to take the place of macro-planning it is useful to catalogue the reasons why the latter failed in order that similar errors may not be repeated:

-Plans were made with projects that were not fully prepared, some of them at such a preliminary stage of investigation that there was no hope that they could ever be commenced, let alone implemented, within the time-scale envisaged (Waterston 1965, ch. 14);

-After the initial publication, perhaps, there was not enough political support to ensure that the Plan was adhered to. Planning became a separate and increasingly disregarded branch of government, only one among many departments competing for a hearing (Leys 1972);

-Political disturbances dominated decisionmaking. A new government refused to take responsibility for the plans of the old, and introduced a new programme (Waterston 1969);

- The Military took over and ignored procedure;

-An economic crisis (such as the five-fold increase in oil prices and the depression which ensued), made nonsense of the economic predictions on which planning depended;

-The planners have been poor communicators. In particular they have failed to work with the sectoral ministries who have to carry out the projects;

-In a mixed economy, the private sector behaved differently than predicted;

-Data on which the plan was based became out of date;

-There was no machinery for marrying the Plan and the budget (Caiden and Wildavsky 1974).

Most of these criticisms derived from a simple time-lag between the preparation of the Plan and the decision date for action. The commonsense conclusion, that the Plan must be made subject to total revision every year, has been accepted by only a few governments (notably that of France) but by every commercial concern that operates medium-term planning. A recent survey remarked, as a criticism, that in France the objectives of a five year plan were rarely the same at the end of five years as at the beginning (Streeten 1976). Yet nothing could be more unreasonable than to suppose that during a period of three, five or seven years, the balance of payments constraints, business cycle, market opportunities, and above all political objectives, would remain unchanged. A Plan system based on project evaluation, therefore, must be above all adaptable.

Discipline however there must be, if ministers and generals are not simply to do as they please with the country's resources. The prime discipline must be that of the Budget. Subservient to the planned availability of funds in a given period, the project evaluation procedure must insist that nothing enters the budget without prior acceptance by the organs of government designated for that purpose. Discipline has to be no less strict, but more workable, than that of the macro-planners. Under the old system it was hoped that nothing would enter the budget which was not in the Plan; in a project planning system, that nothing should enter which had not been judged to add more to the nation's resources than it takes away from them.

Problems of communication with ministries and the private sector remain, and indeed, could become worse. A ministry which has seen its pet projects rejected or reduced will thereafter have a vested interest in the Plan's breakdown; but if the system is one of rolling planning it can revise the project and present it again: the cause for hostility is thus reduced. On the other hand, a COPE may be seen as an organ of delay and interference; the need to avoid this charge requires special attention to monitor progress through government so that delay is minimised. 
Understanding with sectoral ministries can be helped if the COPE has sufficient manpower to assist sectoral ministries in preparing difficult projects for submission.

Even when a rolling plan system is established in a profit maximising corporation, the powers of inertia tend to calcify the projects and strategies unless special care is taken to prevent this. ${ }^{4}$ Such a system needs to have adaptability written into it:

1. Every year, before the budget exercise, the COPE needs to have thoroughly evaluated and approved the projects for which first expenditures are to commence in the following budget year. Naturally the more important projects go to a committee of the Cabinet for final approval; responsibility for projects below a certain expenditure limit can be delegated to subordinate (provincial) or independent (parastatal) bodies. To prevent a logjam of work, it is desirable that sessions be held throughout the year, e.g. quarterly.

2. In the same period, all projects due to commence in the succeeding years of the rolling plan and all expenditures already committed from previous years, must be properly re-appraised for possible savings, alternatives, cost escalation and above all, economic viability. In a five year rolling plan, new projects and expenditures proposed for first expenditures in the final year must be appraised for the first time. The improvement of the data base for appraisal is continuous as the projects approach their year of commencement.

3. National objectives by which projects are judged must be redefined annually. Formally they are unlikely to change, but the weights which governments attach to particular subsidiary objectivesincome redistribution to the poor or to a restive region, economic self-sufficiency, foreign exchange earning, etc-will certainly change from year to year. Since politicians are not accustomed to expressing these weights quantitatively, a qualitative 'State of the Nation' statement must do instead, reinforced by interpretative circulars from the centre about changing emphases in government policy.

4. The economists meanwhile will have worked on updating the objectively determined shadow prices like the shadow wage rates for different classes of labour, foreign exchange premia, accounting prices and conversion factors, test rates of discount and so on. Since these will, realistically, fluctuate with the trade cycle and the balance of payments, less time and economic skill need be invested in their calculation than academic

\footnotetext{
4 In principle, British Airways' planners present a completely
} new Five Year Plan every year. economists are wont to think. As Tinbergen said about accounting prices generally (Tinbergen, 1958:40) the test rate of discount, if it produces too many projects, can always be adjusted upwards.

5. In the meantime, a quite different type of exercise needs to be conducted among the sectoral and regional ministries whose task it is to feed the planners with projects and whose participation must be assured, since they will implement the projects. Each sector or region is encouraged to draw up its own perspective plan, on optimistic and pessimistic assumptions, complete with projects, programmes, alternatives and policy proposals. It is usual to assign dates in such a plan, but a system of trigger-point planning, such as is used in airport planning, is really more useful in the context of the adaptable mechanism here proposed. Realism demands a) that each ministry maintains a more sanguine attitude to growth than is likely to be justified by the (public) funds available. This is necessary if the COPE is to have the required shelf of projects from which the best can be chosen for internal or external finance; b) that to prevent dissatisfaction, their representatives take part in the budget allocation discussions. It follows that sectoral perspective plans, taken as a whole, will not be internally consistent with forecasts for macro-economic identities such as domestic savings. Insofar as they are also inconsistent with one another, this will give early warning of likely conflict over resource use, e.g. of land or foreign exchange.

6. Is there then no use for the internally consistent well-balanced growth models and the skills of the modellers? Yes indeed, for financial planning still requires them, and particularly the forward planning of the aid-givers. For them, after all, fixed term planning was in large part established. It has to be clear, however, that these models represent no more than the best forward estimate of financial requirements and of the economic growth which is expected to result. These too need to be periodically updated.

7. Another element of the fixed year plans, though it always sat there uneasily, is the series of programmes to achieve particular objectives, like housing or localisation or rural revival. A 'programme' is here defined as a series of interrelated projects not yet identified, but expected to be identified later, perhaps by some junior official like a development bank's loans officer. These programmes can best be dealt within a medium-term context.

8. A final purpose of medium-term planning was that of communicating to the people that its 
government, while recognising their lack of jam today, was aware of the need for jam and had laid plans to provide it tomorrow. Popular cynicism about planning has made this less effective a message than once it was, but the need for a message continues. Public relations specialists in developing countries might look afresh at the effectiveness of the planning medium as a means of communication and ask themselves whether the new approach suggested here does not give them a better vehicle. Governments after all should be seen to plan every year and not anly every quinquennium.

The model proposed above is hardly revolutionary. Paragraph 1 is in operation, more or less, in Pakistan, and 2 in France. Many countries, for instance those in East Africa, have made use of an annual economic survey or a pre-budget statement from the finance ministry on the Annual Capital Plan (paragraph 3). Bangladesh reviews all its shadow prices biennially (paragraph 4). Many countries have regional and sectoral perspective plans (5); in the Seychelles the author found that the permanent civil servants, the class which professional planners found most recalcitrant in the early years of planning, were generally eager to present their own long-term sectoral aims in this form. Paragraphs (6), (7) and (8) are elements in the old model of the Plan, the updating of financial requirements being a responsibility of aid consortia. Only periodic updating of project shadow prices and weights is hardly established yet. But as will be seen elsewhere in this issue, a beginning is being made.

\section{DISASTER RESEARCH UNIT OCCASIONAL PAPERS}

\begin{tabular}{|c|c|c|c|c|}
\hline & \multicolumn{2}{|c|}{$\begin{array}{l}\text { Price, Incl. domestic or overseas } \\
\text { surface postage }\end{array}$} & \multicolumn{2}{|c|}{$\begin{array}{l}\text { Price, Incl. airmail overseas } \\
\text { postage }\end{array}$} \\
\hline & $\mathbf{f}$ & $\$$ & $\mathbf{f}$ & $\$$ \\
\hline 1. Bibliography of Disaster Reference Material & & OF PRINT & & \\
\hline $\begin{array}{l}\text { 2. Disaster Management with Special Reference to } \\
\text { Predisaster Planning }\end{array}$ & & OF PTINT & & \\
\hline $\begin{array}{l}\text { 3. Proposals for a Working Method of Indigenous } \\
\text { Resource Co-ordination as a Part of a Predisaster Plan }\end{array}$ & & OF PRINT & & \\
\hline 4. Some Definitions of Disaster & $1 \cdot 50$ & $3 \cdot 00$ & $2 \cdot 50$ & $5 \cdot 00$ \\
\hline 5. A Philosophy of Planning & 0.65 & $1 \cdot 30$ & 1.00 & $2 \cdot 00$ \\
\hline $\begin{array}{l}\text { 6. Gakarara-A Study in the Development of Under- } \\
\text { development }\end{array}$ & & OF PRINT & & \\
\hline 7. Flixborough-the Human Response (reprinted) & 0.85 & $1 \cdot 70$ & $1 \cdot 50$ & $3 \cdot 00$ \\
\hline 8. African Drought--A Review & & OF PRINT & & \\
\hline $\begin{array}{l}\text { 9. Report of Mission to Assess the Hurricane Factor for } \\
\text { Planning Purposes in Fiji }\end{array}$ & & OF PRINT & & \\
\hline 10. A Study in Predisaster Planning & $4 \cdot 00$ & 8.00 & $7 \cdot 00$ & $14 \cdot 00$ \\
\hline $\begin{array}{l}\text { 11. Towards an Explanation and Reduction of Disaster } \\
\text { Proneness }\end{array}$ & & OF PRINT & & \\
\hline 12. A Bibliography of Precautionary Planning & $3 \cdot 25$ & $6 \cdot 50$ & 6.00 & $12 \cdot 00$ \\
\hline $\begin{array}{l}\text { 13. A Primer of Precautionary Planning for Natural } \\
\text { Disaster }\end{array}$ & $1 \cdot 75$ & $3 \cdot 50$ & $2 \cdot 75$ & $5 \cdot 50$ \\
\hline 14. Natural Hazards in the Windward Islands & $1 \cdot 50$ & 3.00 & $2 \cdot 50$ & 5.00 \\
\hline
\end{tabular}

All Enquiries to:

Project Planning Centre for Developing Countries, University of Bradford, Bradford, BD7 1DP, West Yorkshire. 